\title{
Indications and prognosis of fetal extractions by caesarean section before 34 weeks of amenorrhea in black African context
}

\begin{abstract}
Objectives: To analyze the clinical features and prognosis of fetal extractions by caesarean section before 34 weeks of amenorrhea.

Materials and methods: This is a retrospective and analytical study of 196 cases of women who gave birth by caesarean section at the maternity of Sylvanus Olympio's University Hospital of Lomé, before 34 weeks of amenorrhea from 1st January 2009 to 31st December 2011 .

Results: Fetal extraction by caesarean section before 34 weeks of amenorrhea has represented $3.6 \%$ of caesarean sections rate. Hypertensive disease during pregnancy and its complications (gestational hypertension, preeclampsia, eclampsia, and placenta abruptio) were in $61.8 \%$ of cases, the primary indication of fetal extractions before 34 weeks. The premature mortality rate was $9.8 \%$ and neonatal infection was the most deadly disease (52.4\%). The first week of life was the most fatal with $61.9 \%$ of cases of early neonatal death. The minimum gestational age of 30 weeks of amenorrhea plus 6 days and more, allowed better survival as well as birth weight above $1300 \mathrm{~g}$
\end{abstract}

Conclusion: Fetal extraction could be considered with confidence in the center if gestational age is about 30 weeks of amenorrhea plus 6 days or more and if the birth weight is over 1300 grams. Emphasis should be put more on the prevention of infections and on the improvement of the technical platform for management of premature newborns.
Volume 4 Issue 2 - 2016

\author{
Amah Biova Adama-Hondegla,' Aboubakari \\ AS, ${ }^{2}$ Egloh AS, I Fiagnon K,' Bassowa A, ${ }^{2}$ \\ Akpadza $\mathrm{K}^{\prime}$ \\ 'Department of Gynecology and Obstetrics, University of Lome, \\ Togo \\ ${ }^{2}$ Department of Gynecology and Obstetrics, University hospital \\ Center of Kara,Togo
}

\begin{abstract}
Correspondence: Amah Biova Adama $\square$ Hondegla, Department of Gynecology and Obstetrics at Sylvanus Olympio University Hospital Center, Faculty of Health Science, University of Lom?, 0IPO BOX 4898 Lom?, Togo, Tel 00(228)90183939. Email rocadama@yahoo.fr
\end{abstract}

Received: October 24, 2015 | Published: February 04, 2016

Keywords: caesarean section, premature birth, 34 weeks of amenorrhea, neonatal prognosis, black africa

\section{Abbreviation: WA: weeks of amenorrhea \\ Introduction}

There are more than twenty years ago, caesarean sections for fetal distress were not performed if the fetal weight was less than $1000 \mathrm{~g}$ or gestational age less than 28 weeks of amenorrhea (WA). ${ }^{1}$ Today, with advances in neonatology, survival to birth weight around 500 grams or gestational ages from 22 weeks of amenorrhea have been reported. This leads practitioners to perform caesarean sections in terms of pregnancy ever earlier. However, despite this progress, premature delivery still brings problems around the world, including in developed countries where the birth of these fragile beings occurs in maternities of rank III; a rare organizations in the sub-Saharan countries where technical facilities are lacking despite local human skills. ${ }^{2,3}$

Currently in Africa, 41 in 1,000 babies die before the age of one month (mostly prematurity). ${ }^{4}$ In Togo, the mortality of preterm infants was estimated to $31.1 \%$ in $1997 .{ }^{5}$ There are obstetric emergencies that may threaten maternal survival to the point of deciding the termination of pregnancy before term. Foremost among these conditions were included hypertensive disease and its complications (eclampsia, placenta abruption) and placenta praevia bleeding. The extraction decision prematurely by caesarean section in resource-limited countries should be based on data of the survival of these newborns in health contexts with similar epidemiological profiles. What leads to these extraction by cesarean section before term and what is the neonatal prognosis of these fetus in black African environment?"
This study was undertaken to identify key conditions requiring fetal extraction by caesarean section before 34 weeks of amenorrhea and to describe the early neonatal prognosis of these premature babies at the Sylvanus Olympio's University Hospital of Lomé (Togo, West Africa)

\section{Materials and methods}

This is a retrospective, descriptive and analytical study on the preterm cesarean deliveries performed in the Clinic of Obstetrics and Gynecology of the Sylvanus Olympio's University Hospital of Lomé and its Pediatrics Service (neonatal unit). It covered the period from 1st January 2009 to 31st December 2011 (a period of 3 years). The Clinic of Obstetrics and Gynecology of the Sylvanus Olympio's University Hospital of Lomé is a maternity of rank "III", and provides full emergency obstetrical and neonatal care (full EmONC) to patients referred from various health facilities in Togo. At the time of this study, intra alveoli injection of surfactant was not performed in the neonatal emergency unit care. Hundred ninety-six medical records of women who underwent cesarean section for fetal extraction before 34 weeks of amenorrhea, records of newborns in neonatology and the obstetrics surgical records during the study period were collected. The various parameters studied were the epidemiological and obstetrical data, the cesarean indications and neonatal prognosis according to the gestational age and newborns birth weight.

\section{Statistical analysis}

Data collection was made with a survey sheet, compiled and analyzed using Epi info version 3.5 software. For the comparison of 
certain variables, chi-2 tests and Fisher were used. The significance level was set at $\mathrm{p}<0.05$.

\section{Results}

\section{Frequency of the fetal extractions by caesarean section before 34 WA}

It was recorded during the study period, 5475 caesarean sections including 196 cesarean before 34 weeks of amenorrhea; such a rate of $3.6 \%$. These one hundred ninety-six (196) pregnancies had allowed the delivery of 215 preterm newborns with $91.2 \%$ of singleton pregnancies against $8.8 \%$ of twin pregnancies. The average age of pregnant women who had underwent caesarean section before 34 weeks of amenorrhea was 28.8 years with extremes of 15 and 44 years.

\section{Indications for cesarean section}

The indications for cesarean section in this study were: preeclampsia and eclampsia (43.4\%), premature rupture of membranes with total absence of amniotic fluid (17.3\%), placenta abruptio (14.3\%), fetal distress $(10.2 \%)$, intra uterine growth restriction $(6.1 \%)$, placenta praevia bleeding (4.6\%); others indications (failure of tocolysis with breech presentation in primigravida, or with scarred uterus in twins pregnancy) represented $4.1 \%$ of cases. Out of 196 patients, 152 $(77.5 \%)$ had received antenatal corticotherapy with two days injection of $12 \mathrm{mg}$ of Betamethasone (For the last 22.5\%, the acute aspect of the pregnant women's affection did not permit any delay).

\section{Newborns characteristics}

In Table 1, were reported newborns gestational age and birth weight. It appeared that, $49.3 \%$ of newborns were very preterm $(<32$ weeks of gestation), $34.9 \%$ were very low birth weight $(<1500 \mathrm{~g})$ and the majority (98.1\%) were low birth weight. Distribution of newborns according to gestational age and birth weight were shown in Table 2. Trophicity was identified according to the table of Shinozuka. ${ }^{6}$ Of the 215 premature infants, $36(16.7 \%)$ were hypotrophic (small for gestational age)

Table I Newborns characteristics

\begin{tabular}{ll}
\hline Gestationnel Age (WA) & $\begin{array}{l}\text { Frequency (\%) } \\
\mathbf{N}=\mathbf{2} \text { I5 }\end{array}$ \\
\hline$<29$ & $13(6)$ \\
{$[29-30]$} & $15(6.9)$ \\
{$[30-31]$} & $18(8.4)$ \\
{$[31-32]$} & $60(27.9)$ \\
{$[32-33]$} & $46(21.4)$ \\
{$[33-34]$} & $63(29.3)$ \\
Birth weight (g) & \\
$<900$ & $4(1.9)$ \\
{$[900-1100]$} & $9(4.2)$ \\
{$[1100-1300]$} & $24(11.2)$ \\
{$[1300-1500]$} & $38(17.7)$ \\
{$[1500-1700]$} & $27(12.6)$ \\
{$[1700-1900]$} & $48(22.3)$ \\
{$[1900-2100]$} & $47(21.9)$ \\
{$[2100-2300]$} & $12(5.6)$ \\
{$[2300-2500]$} & $2(0.9)$ \\
$\geq 2500$ & $4(1.9)$ \\
\hline
\end{tabular}

WA, Weeks of Amenorrhea

\section{Neonatal prognosis}

Main affections on admission: Seventy-nine of 215 neonates $(36.7 \%)$ had presented, on admission, neonatal pathologies that were represented by $63(79.7 \%)$ cases of neonatal infections, $8(10.1 \%)$ cases of respiratory distress syndrome, $3(3.8 \%)$ cases of neonatal jaundice, $3(3.8 \%)$ cases of disease of the hyaline membranes, 1 $(1.3 \%)$ cases of necrotizing ulcerative enterocolitis and $1(1.3 \%)$ cases of cyanogen heart disease.

The major diagnosis and complications that occurred during the hospitalization of the newborns were: neonatal jaundice $(37.9 \%)$, neonatal infection $(28.7 \%)$, neonatal anemia $(10.3 \%)$, the necrotizing ulcerative enterocolitis $(9.2 \%)$, neonatal malaria $(9.2 \%)$, edema and ascites syndrome $(2.3 \%)$, Hirschsprung disease $(1.2 \%)$ and interventricular communications (1.2\%).

Lethality: Twenty-one infants on two hundred and fifteen (9.8\%) had died. Referring to the 5475 newborns born by cesarean section during our study period, the mortality rate of preterm extractions by caesarean section before 34 WA is 38 deaths per 10,000 live births.

Factors related to neonatal mortality: According to Table 3, death of newborns had occurred within the first week of life in $61.9 \%$ of cases and the neonatal affection was the main cause of death (52.4\%).

It was reported in Table 4, the mortality of newborns according to gestational age, birth weight and trophicity.

Table 2 Distribution of newborns according to gestational age and birth weight

\begin{tabular}{|c|c|c|c|c|c|c|}
\hline & $<1000 \mathrm{~g}$ & $\begin{array}{l}1000- \\
1250 \mathrm{~g}\end{array}$ & $\begin{array}{l}1250- \\
1500 \mathrm{~g}\end{array}$ & $\begin{array}{l}1500- \\
1750 \mathrm{~g}\end{array}$ & $\begin{array}{l}1750- \\
2000 \mathrm{~g}\end{array}$ & $>2000 \mathrm{~g}$ \\
\hline$<29 W A$ & 4\# & 4 & 3 & 0 & 0 & 0 \\
\hline [29-30WA] & $3 \#$ & 2 & 8 & I & 2 & I \\
\hline [30-32WA] & $2 \#$ & $8 \#$ & 22 & 19 & 22 & 5 \\
\hline [32-34WA] & $2 \#$ & $6 \#$ & $\mathrm{II} \#$ & 9 & 58 & 23 \\
\hline
\end{tabular}

WA, Weeks of Amenorrhea; g, grams

\#hypotrophic (small for gestational age) according to Shinozuka data. ${ }^{6}$

Table 3 Age and causes of newborns death

\begin{tabular}{ll}
\hline New borns death & $\begin{array}{l}\text { Frequency (\%) } \\
\text { N= 2 I }\end{array}$ \\
\hline $\begin{array}{l}\text { Age at Death } \\
\leq 7 \text { days }\end{array}$ & $13(6 \mathrm{I} .9)$ \\
$8-$ I 4 days & $5(23.8)$ \\
$\geq$ I 4 days & $3(14.3)$ \\
Causes of Death & \\
Neonatal Infection & $\mathrm{I} \mid(52.4)$ \\
Neonatal Anemia & $5(23.8)$ \\
Respiratory Distress & $5(23.8)$
\end{tabular}

Table 4 Mortality of newborns according to gestational age, birth weight and trophicity

\begin{tabular}{llll}
\hline $\begin{array}{l}\text { GestationalAge } \\
\text { (Weeks of Amenorrhea) }\end{array}$ & $\begin{array}{l}\text { Dead } \\
\mathbf{N}=\mathbf{2} \text { I }\end{array}$ & $\begin{array}{l}\text { Alive } \\
\mathbf{N}=194\end{array}$ & P values \\
\hline$<29$ & $\mathbf{n}(\%)$ & $\mathbf{n}(\%)$ & \\
{$[29-30]$} & $4(19.05)$ & $\mathrm{II}(5.67)$ & 0.045 \\
{$[30-31]$} & $3(14.29)$ & $\mathrm{I} 5(7.73)$ & 0.395 \\
{$[31-32]$} & $2(9.52)$ & $58(29.90)$ & 0.070 \\
{$[32-33]$} & $2(9.52)$ & $44(22.68)$ & 0.260 \\
{$[33-34]$} & $2(9.52)$ & $61(31.44)$ & 0.042 \\
\hline
\end{tabular}


Table continued..

\begin{tabular}{|c|c|c|c|}
\hline & $\begin{array}{l}\text { Dead } \\
\mathrm{N}=2 \text { I }\end{array}$ & $\begin{array}{l}\text { Alive } \\
N=194\end{array}$ & $P$ values \\
\hline \multicolumn{4}{|l|}{ Birth Weight(grams) } \\
\hline$<900$ & $0(0.0)$ & $4(2.06)$ & 1.00 \\
\hline$[900-1100]$ & $5(23.8 I)$ & $4(2.06)$ & 0.0005 \\
\hline$[1100-1300]$ & $6(28.57)$ & $18(9.28)$ & 0.017 \\
\hline$[1300-1500]$ & $2(9.52)$ & $36(18.56)$ & 0.382 \\
\hline$[1500-1700]$ & $5(23.8 I)$ & $22(\mathrm{II} .34)$ & 0.154 \\
\hline$[1700-1900]$ & $0(0.0)$ & $48(24.74)$ & 0.005 \\
\hline$[1900-2100]$ & I (4.76) & $46(23.7 I)$ & 0.051 \\
\hline$[2100-2300]$ & $2(9.52)$ & $10(5.15)$ & 0.331 \\
\hline$[2300-2500]$ & $0(0.0)$ & $2(1.03)$ & 1.000 \\
\hline$>2500$ & $0(0.0)$ & $4(2.06)$ & 1.000 \\
\hline \multicolumn{4}{|l|}{ Trophicity } \\
\hline Small for Gestational age & $17(80.95)$ & $19(9.79)$ & $10^{-10}$ \\
\hline
\end{tabular}

\section{Discussion}

Fetal extraction before 34 weeks of gestation is a prematurity induced by cesarean section. It is often practiced when the pregnancy becomes threatening for the mother or when the risk of the infant to be born prematurely is smaller than the one of remaining in utero. ${ }^{7}$ The term of 34 weeks of amenorrhea is a "cape of good hope" for the survival of premature infants, since the surfactant secretion in the lung alveoli is at its highest level in the fetus; this can prevent hyaline membrane disease for the premature neonate. ${ }^{2,8}$

It was recorded during the study period (2 years), a rate of $3.6 \%$ of fetal extraction by cesarean section before 34 weeks of amenorrhea. The cesarean rate has increased in recent decades and remains particularly high in premature births. It was shown that more than half of infants born before 34 weeks of gestation in the United States were delivered by caesarean section. ${ }^{9}$ Most often, preterm fetal extraction result of various etiological factors which can be divided into maternal, fetal or mixed causes. Preeclampsia and eclampsia, premature rupture of membranes with total absence of amniotic fluid, placenta abruption associated with fetal distress accounted for the main indications $(85.2 \%)$ of cesarean section before 34 weeks of amenorrhea in this study. The others indications (premature labor with breech presentation in primigravida, or with scarred uterus containing twins pregnancy, intra uterine growth retardation and placenta praevia bleeding) accounted for $14.8 \%$ of cases. However, the percentages vary from one study to another. ${ }^{10,11}$ In the study of Högberg \& Holmgren, ${ }^{12}$ the cesarean rate for maternal or fetal indication was $98 \%$ in the case of pre-eclampsia/eclampsia. The fear of the occurrence of preeclampsia/eclampsia complications often leads obstetricians to perform cesarean delivery before 34 weeks, even if the infants born preterm are very low birth weight or not. ${ }^{2}$

About $49.3 \%$ of newborns were very preterm $(<32$ weeks of amenorrhea), $34.9 \%$ were very low birth weight $(<1500 \mathrm{~g})$ and the majority $(98.1 \%)$ were low birth weight. The management of these very premature raises serious problems because the premature newborns are particularly susceptible to infection due to the immaturity of their immune system. ${ }^{2}$ The neonatal infection represented the first pathology during hospitalization (a rate of 79.7\%) in this study. The reported figures remain low compared to those found in Cameroon $(52 \%) .{ }^{13}$ Neonatal jaundice, caused by the increased bilirubin in the blood of the premature infants, was the second most encountered disease in this series with a proportion of $37.9 \%$.

It was noted a survival rate of $90.2 \%$ in premature extracted before 34 weeks of amenorrhea. Lower survival rates were found by Ngo
Tonye $(72.7 \%)$ in $2008^{14}$ in the same center. This could be attributed to improvements in obstetric and neonatal intensive care. According to the literature, large variations in the survival rates of premature exist among different geographical regions as well as among racial and ethnic groups. ${ }^{2}$

Neonatal infection and respiratory distress was the most deadly pathology of the study with respectively $42.9 \%$ and $23.8 \%$ lethality. These results are in agreement with those of Bobossi ${ }^{3}$ in Congo. Respiratory distress syndrome is associated with surfactant deficiency. Babies delivered by cesarean section before 34 weeks of amenorrhea had greater risk to respiratory distress than babies born vaginally because hormonal and physiological changes associated with labor are necessary for lung maturation in neonates. ${ }^{15}$ In these cases, $77.5 \%$ of patients of this study had received antennal corticoid injection with two days injection of $12 \mathrm{mg}$ of Betamethasone. It is noticed that the severity of mother's pathology rarely allow this preventive injection for fetus lungs maturation; this has been the case with $22.5 \%$ remaining.

In neonatal period (first 28 days), premature infant are more likely than infants born full term to die. It was recorded in this series, $61.9 \%$ of deaths during the first week against $23.8 \%$ in the second week. In the study of Balaka et al. ${ }^{16}$ the letality rate was $30.1 \%$ with $29 \%$ the first 7 days of life and $1.1 \%$ from eighth to 28 th day of life. ${ }^{16}$ This situation reveals a high mortality rate in the first 7 days of life among preterm infant. ${ }^{17}$

Survival rate in the age group of less than 29 weeks was $38.5 \%$. But gradually as gestational age was increasing, the survival rate increased too. Thus the survival rate fell from $73.4 \%$ to $83.4 \%$ and to $96.7 \%$ for gestational ages respectively. The last gestational age range which was still associated with a significant mortality rate during neonatal period, was 29 to 30 weeks of amenorrhea $(19.05 \%$ vs 5.67 ; $p<0.045)$. So the gestational age which was supposed to improve survival in this study must be the one from 30 weeks of amenorrhea plus one day. These results are consistent with others studies which had shown a survival rate around $94 \%$ in premature infants born between 27 and 31 WA and of $60 \%$ among 25 weeks of amenorrhea. ${ }^{7,18}$ Apart gestational age, other factors such as birth weight and trophicity were also involved in premature prognosis. According to the results, lethality increases with decreasing birth weight except less than $900 \mathrm{~g}$ which include $100 \%$ survival. Between 900 and $1100 \mathrm{~g}$, lethality was $44.5 \%$. The minimum preterm birth weight around which a better survival could be expected was above $1300 \mathrm{~g}$ because a birth weight of 1299 grams was still significantly associated to neonate mortality $(28.57 \%$ vs $9.8 \% ; \mathrm{p}<0.017)$. In addition, premature small for gestational age (hypotrophic) are more likely to die than eutrophic infants; the difference of the two groups was very significant $(p<10-10)$. The literature data shows that mortality rates increase proportionally with decreasing gestational age or birth weight; because premature babies are fragile beings and their survival in extreme cases are not without sequelae. ${ }^{2,19}$

\section{Conclusion}

Fetal extractions before 34 weeks of amenorrhea accounted for $3.6 \%$ of all cesarean sections during the study period. Eclampsia and hemorrhagic diseases of the third quarter of pregnancy were the main causal conditions. The minimum gestational age and birth weight at which the survival of premature infants could be considered was about 30 weeks of amenorrhea plus 6 days and beyond 1300grams, respectively. The need for better collaboration between obstetricians and pediatricians for prevention in neonate infections and improving 
the technical platform of premature newborns management should improve the prognosis for these infants extracted before 34 WA.

\section{References}

1. Langer B, David E, Ancel PY, et al. Critères d'extraction fœtale avant terme lors de retard de croissance in utero in Extrait des Mises à jour en Gynécologie et Obstétrique- TOME XXV publié le 6.12.2001.

2. Behrman RE, Butler AS. Preterm birth: causes, consequences, and prevention. Institute of Medicine (US) Committee on Understanding Premature Birth and Assuring Healthy Outcomes. Washington, D.C. National Academies Press, USA; 2007.

3. Bobossi-Serengbe G, Mbongo-Zindamoyen AN, Dimer H, et al. Les nouveau-nés de faibles poids de naissance à l'unité de néonatologie du complexe pédiatre de Bangui (RCA): devenir immédiat et pronostic. Med Afr Noire. 2000;47(4):191-195.

4. Organisation Mondiale de la Santé (OMS). Santé du nouveau-né : condition essentielle à la survie de l'enfant. Genève; 2006. 52 p.

5. Boko A. La prématurité au CHU Tokoin. Thèse médicale, Université du Bénin; 1997.

6. Shinozuka Estimation du poids foetal.

7. Rozé J-C, Muller J-B, Baraton L. Point sur la grande prématurité en 2007. Réanimation. 2007;16(5):408-412.

8. Spong CY, Mercer BM, D'Alton M, et al. Timing of Indicated latepreterm and early-term birth. Obstet Gynecol. 2007;118(2):323-333.

9. Werner EF, Savitz DA, Janevic TM, et al. Mode of delivery and neonatal outcomes in preterm, small-for-gestational-age newborns. Obstet Gynecol. 2010;120(3):560-564.
10. Fournier P. Prématurité spontanée ou induite: quelle influence sur l'avenir du nouveau-né? Gynecology and obstetrics. 2010.

11. Pambou O, Ntsika-Kaya P, Ekoundzola JR, et al. Naissances avant terme au CHU de Brazzaville. Cahiers Santé. 2006;16(3):185-189.

12. Högberg U, Holmgren PA (2007) Infant mortality of very preterm infants by mode of delivery, institutional policies and maternal diagnosis. Acta Obstet Gynecol Scand. 2006;86(6):693-700.

13. Tietche, Koki NDombo P, Kago IA, et al. Facteurs de mortalité des nouveau-nés de petit poids de naissance à l'Hôpital central de Yaoundé. Annales de Pédiatrie. 1994;41(4):259-263

14. Ngo Tonye CM. Accouchement prématuré à la maternité du CHUTokoin: facteurs de risque et pronostic. Thèsemédicale Université de Lomé, n ${ }^{\circ}$ 18. 2008.

15. Alfirevic Z, Milan SJ, Livio S. Caesarean section versus vaginal delivery for preterm birth in singletons. Cochrane Database Syst Rev. 2013;6: CD000078.

16. Balaka $\mathrm{B}$, Baeta $\mathrm{S}$, Agbèrè $\mathrm{AD}$, et al. Facteurs de risque associés à la prématurité au CHU de Lomé, Togo. Bull Soc Pathol Exot. 2002;95(4):280-283.

17. Beck S, Wojdyla D, Say L, et al. The worldwide incidence of preterm birth: a systematic review of maternal mortality and morbidity. Bull WHO. 2010;88(1):1-80.

18. ZupanSimunek V, Razafimahefa H, Chabernaud J-L, et al. Avancées médicales et progrès techniques en réanimation néonatale. $E M C$ consulte. 2007:1-20.

19. Larroque B, Ancel PY, Marret S, et al. Neurodevelopmental disabilities and special care of 5-year-old children born before 33 weeks of gestation (the EPIPAGE study): a longitudinal cohort study. Lancet. 2008;371(9615):813-820. 